\title{
InAs Quantum Dots of Engineered Height for Fabrication of Broadband Superluminescent Diodes
}

\author{
S. Haffouz and P.J. Barrios \\ Institute for Microstructural Sciences, National Research Council of Canada, \\ Ottawa, Ontario, \\ Canada
}

\section{Introduction}

Superluminescent diodes (SLDs) are of great interest as optical sources for various field applications like fibre-optic gyroscopes (Culter et al, 1980), optical time-domain reflectometry (Takada et al, 1987), sensing systems (Burns et al, 1983) (such as Faraday-effect electric current sensors and distributed Bragg-grating sensor systems) and short and medium distance optical communication systems (Friebele \& Kersey, 1994). One of the most attractive applications of SLDs has emerged after the successful demonstration of the optical coherence tomography (OCT) technique, and identification of its advantages compared to other imaging techniques in medical research and clinical practices. OCT is a real time and non-invasive imaging technique that uses low-coherence light to generate resolution down to the sub-micron-level, two- or three-dimensional cross-sectional images of materials and biological tissues. The earliest version of the OCT imaging technique was demonstrated in 1991 by Huang and co-workers (Huang et al, 1991), by probing the human retina ex vivo. Imaging was performed with $15 \mu \mathrm{m}$ axial resolution in tissue using a light source with a central wavelength of $830 \mathrm{~nm}$. Two years later, in vivo retinal images were reported independently by Fercher et al. (Fercher et al, 1993) and Swanson et al (Swanson et al, 1993). Although 800nm OCT systems can resolve all major microstructural layers of tissues, image quality can be severally degraded by light scattering phenomena. In low-coherence interferometry, the axial resolution is given by the width of the field autocorrelation function, which is inversely proportional to the bandwidth of the light source. In other words, light sources with broadband spectra are required to achieve high axial resolution. Although at longer wavelengths the bandwidth requirement increases, there is a significant advantage in using light sources of longer central wavelengths for which the light scattering is significantly reduced.

In recent few years, broadband light sources around $1 \mu \mathrm{m}$ have received considerable attention for their use in medical imaging technologies. It is due to the optimal compromise between water absorption and human tissue scattering that the 1000-1100 nm wavelength range has been proposed, and demonstrated, to be more suitable for OCT applications as compared to those that use a light source with a central wavelength of $800 \mathrm{~nm}$ (Pavazay et al, 
2003; Pavazay et al, 2007). There are a myriad of choices in selecting such OCT light sources i) femtosecond or fiber lasers that are dispersed to produce super-continuum light and swept source lasers (Hartl et al, 2001; Wang et al, 2003), ii) thermal sources, and iii) superluminescent diodes (Sun et al, 1999; Liu et al, 2005; Lv et al, 2008; Haffouz et al, 2010). Although the reported OCT tomograms with the highest axial resolution $(1.8 \mu \mathrm{m})$ were so far achieved in research laboratories with a photonic crystal fibre based source (Wang et al, 2003), superluminescent diodes are considerably lower in cost and complexity as well as being smaller in size, which makes them more attractive for mass production. Superluminescent diodes utilizing quantum-dots (QDs) in the active region are considered to be excellent candidates as light source for an OCT systems. The naturally wide dimensional fluctuations of the self-assembled quantum dots, grown by the StranskiKrastanow mode, are very beneficial for broadening the gain spectra which enhances the spectral width of the SLDs. On the other hand, the three-dimensional carrier confinement provided by the dots' shape results in high radiative efficiency required for the OCT applications.

In this chapter the main governing factors to demonstrate ultrahigh-resolution OCT-based imaging tomographs will be reviewed in the second section. Research advances in the growth processes for engineering the gain spectrum of the quantum dots-based superluminescent diodes will be summarized in the third section of this chapter. Our approach for engineering the bandwidth of multiple stacks of InAs/GaAs QDs will be presented in the fourth section and demonstration of an ultra wide broadband InAs/GaAs quantum-dot superluminescent diodes (QD-SLDs) will be then reported in the last section of this chapter. Our approach is based on the use of SLDs where the broad spectrum is obtained by a combination of slightly shifted amplified spontaneous emission (ASE) spectra of few layers of dots of different heights. Spectral shaping and bandwidth optimization have been achieved and resulted in 3dB-bandwidth as high as $\sim 190 \mathrm{~nm}$ at central wavelength of $1020 \mathrm{~nm}$. An axial resolution of $2.4 \mu \mathrm{m}$ is calculated from our QD-SLDs.

\section{Superluminescent diodes for ultrahigh-resolution optical coherence tomography (UHR-OCT)}

Since its invention in the early 1990s (Huang et al, 1991), OCT enables non-invasive optical biopsy. OCT is a technique that provides in-situ imaging of biological tissue with a resolution approaching that of histology but without the need to excise and process specimens. OCT has had the most clinical impact in ophthalmology, where it provides structural and quantitative information that can not be obtained by any other modality. Cross-sectional images are generated by measuring the magnitude and echo time delay of backscattered light using the low-coherence interferometry technique. The earliest versions of OCT have provided images with an axial resolution of $10-15 \mu \mathrm{m}$. OCT has then evolved very quickly, with two-dimensional (2D) and three-dimensional (3D) microstructural images of considerably improved axial resolution being reported (Drexler et al, 1999). These ultrahigh-resolution OCT systems (UHR-OCT) enable superior visualization of tissue microstructure, including all intraretinal layers in ophthalmic applications as well as cellular resolution OCT imaging in nontransparent tissues. The performance of an OCT system is mainly determined by its longitudinal (axial) resolution, transverse resolution, dynamic range (sensitivity) and data acquisition speed. Other decisive factors like depth penetration 
into the investigated tissue (governed by scattering, water absorption) and image contrast need to be carefully addressed. In addition, for field application, compactness, stability, and overall cost of the OCT system should be considered.

\subsection{Factors governing OCT imaging performance}

In this section we will review the key parameters that are directly or closely related to the light source used in the OCT technique. Other limiting factors, related to other optical, electronic and/or mechanical components can affect the resolution in OCT system when not properly addressed. For more details regarding OCT technology and applications, please refer to the book edited by Drexler and Fujimoto (Drexler \& Fujimoto, 2008).

\subsubsection{Transverse and axial resolution}

As in conventional microscopy, the transverse resolution and the depth of focus are determined by the focused transverse sport size, defined as the $1 / e^{2}$ beam waist of a Gaussian beam. Assuming Gaussian rays and only taking into account Gaussian optics, the transverse resolution can be defined by:

$$
\Delta x=\frac{4 \lambda}{\pi} \frac{f}{d}
$$

where $f$ is the focal length of the lens, $d$ is the spot size of the objective lens and $\lambda$ is the central wavelength of the light source. Finer transverse resolution can be achieved by increasing the numerical aperture that focuses the beam to a small spot size. At the same time, the transverse resolution is also related to the depth of the field or the confocal parameter $b$, which is $2 z_{R}$, or two times the Rayleigh range:

$$
b=2 z_{R}=\frac{\pi \Delta x^{2}}{\lambda}
$$

Therefore, increasing the transverse resolution produces a decrease in the depth of the field, similar to that observed in conventional microscopy. Given the fact that the improvement of the transverse resolution involves a trade-off in depth of field, OCT imaging is typically performed with low numerical aperture focusing to have a large depth of field. To date, the majority of early studies have rather focused on improving the axial resolution.

Contrary to standard microscopy, the axial image resolution in OCT is independent of focusing conditions. In low-coherence interferometry, the axial resolution is given by the width of the field autocorrelation function, which is inversely proportional to the bandwidth of the light source. For a Gaussian spectrum, the axial (lateral) resolution is given by:

$$
\Delta z=\frac{2 \operatorname{Ln}(2)}{\pi} \frac{\lambda^{2}}{\Delta \lambda}
$$

where $\Delta z$ is the full-width-at-half-maximum (FWHM) of the autocorrelation function, , and $\Delta \lambda$ is the FWHM of the power spectrum. 


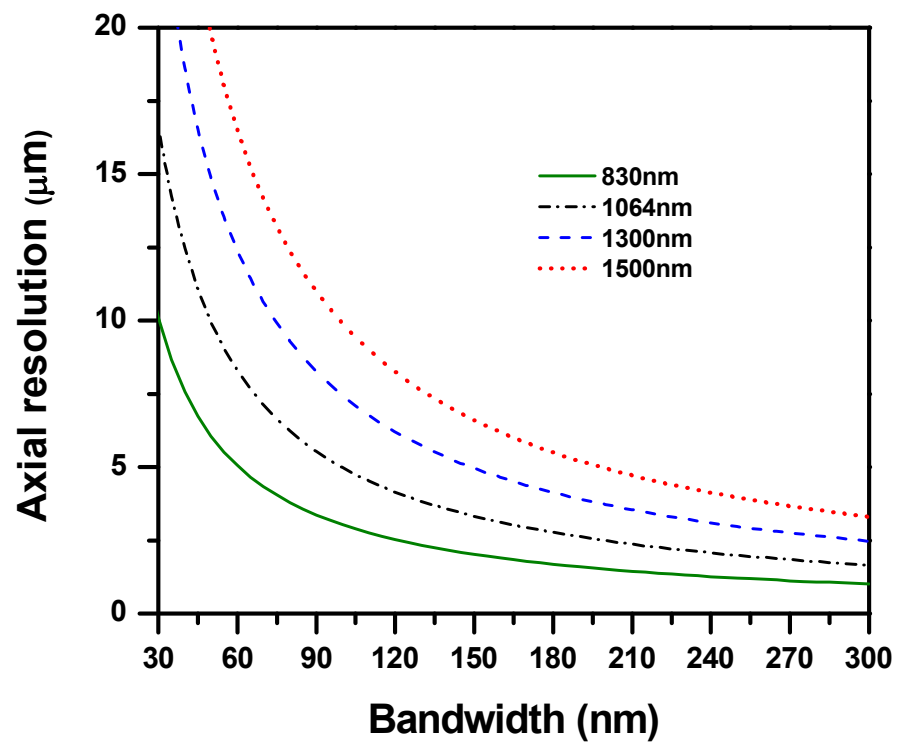

Fig. 1. Axial resolution versus bandwidth of light sources for central wavelengths of 830, 1064,1300 and $1500 \mathrm{~nm}$.

Since the axial resolution is inversely proportional to the bandwidth of the light source, broadband light sources are required to achieve high axial resolution. For a given bandwidth, improving the axial OCT resolution can be also achieved by reducing the central wavelength of the light source (c.f. Figure 1). It should also be noticed that to achieve a given axial resolution the bandwidth requirement is increased at longer wavelengths. For example, to achieve an axial resolution of $5 \mu \mathrm{m}$, the bandwidth required is only $50 \mathrm{~nm}$ at central wavelength of $830 \mathrm{~nm}$, and three times higher when a light source of central wavelength of $1300 \mathrm{~nm}$ is chosen.

\subsubsection{Imaging speed-sensitivity in OCT}

Detection sensitivity (detectable reflectivity) has a significant impact on the imaging speed capabilities of an OCT system. As the scan speed increases, the detection bandwidth should be increased proportionally, and therefore the sensitivity drops. The sensitivity of state-ofthe-art time-domain OCT systems that operate at relatively low imaging speed $(\sim 2 \mathrm{kHz} A-$ line rate), ranges between -105 and $-110 \mathrm{~dB}$. Increasing the optical power of the light source should in principle improve the sensitivity; however, the available sources and maximum permissible exposure levels of tissue represent significant practical limitations. The potential alternative technique for high-imaging speed is the use of Fourier/spectral domain detection (SD-OCT) or Fourier/swept source domain detection (SS-OCT) also known as optical frequency domain imaging (OFDI). The first approach, SD-OCT, uses an interferometer with a low-coherence light source (superluminescent diodes) and measures the interference spectrum using a spectrometer and a high-speed, line scan camera. The second approach, SS-OCT, uses an interferometer with a narrow-bandwidth, frequencyswept light source (swept laser sources) and detectors, which measure the interference 
output as a function of time. Fourier domain detection has a higher sensitivity as compared to time domain detection, since Fourier domain detection essentially measures all of the echoes of light simultaneously, improving sensitivity by a factor of 50-100 times (enabling a significant increase in the imaging speeds).

\subsubsection{Image contrast and penetration depth in OCT}

Tissue scattering and absorption are the main limiting factors for image contrast and penetration depth in OCT technology. Indeed, OCT penetration depth is significantly affected by light scattering within biological tissue, which scales as $1 / \lambda^{k}$, where the coefficient $k$ is dependent on the size, shape, and relative refractive index of the scattering particles. The difference in tissue scattering and absorption provides structural contrast for OCT. Since scattering depends strongly on wavelength and decreases for longer wavelengths, significantly larger image penetration depth can be achieved with light centered at $1300 \mathrm{~nm}$ rather than $800 \mathrm{~nm}$. However, above $1300 \mathrm{~nm}$ the water absorption becomes a problem. So far, the majority of clinical ophthalmic OCT studies have been performed in the $800 \mathrm{~nm}$ wavelength region. Excellent contrast, especially when sufficient axial resolution is accomplished, enables visualization of all major intraretinal layers, but only limited penetration beyond the retina. This limitation is mainly due to significant scattering and absorption phenomena.

Water is the most abundant chemical substance in the human body, accounting for up to $90 \%$ of most soft tissues. The most commonly used wavelength window of low water absorption $\left(\mu_{\mathrm{a}}<0.1 \mathrm{~cm}^{-1}\right)$ for OCT imaging is lying in the $200-900 \mathrm{~nm}$ range. Above $900 \mathrm{~nm}$ the absorption coefficient increases fairly rapidly to reach $\mu_{\mathrm{a}} \sim 0.5 \mathrm{~cm}^{-1}$ at $\sim 970 \mathrm{~nm}$, drops back to $\sim 0.13 \mathrm{~cm}^{-1}$ at $1064 \mathrm{~nm}$, and then continues to increase at longer wavelengths into the mid-infrared. The region of low absorption around 1060nm acts as a 'window' of transparency, allowing near infrared spectroscopic measurements through several centimeters of tissue to be made. For this reason, OCT imaging at $1060 \mathrm{~nm}$ can achieve deeper tissue penetration into structures beneath the retinal pigment epithelium, as well as better delineation of choroidal structure.

\subsection{Light source for ultrahigh resolution OCT}

The light source is the key technological parameter of an OCT system. The performance characteristic of the light source, such as central wavelength, bandwidth, output power, spectral shape, and stability will directly affect the OCT image resolution. For this reason, a proper choice of the light source for optimized performance OCT system is imperative. In the recent years, there has been considerable interest in the use of broadband light sources around $1064 \mathrm{~nm}$ for use in ophthalmic OCT applications. It is due to the optimal compromise between water absorption and human tissue scattering that the $1064 \mathrm{~nm}$ wavelength 'window' has been proposed, and demonstrated, to be more suitable for OCT applications as compared to those that use a light source with a central wavelength of $800 \mathrm{~nm}$ (Povazay et al, 2007). There are a myriad of choices in selecting such OCT light sources i) femtosecond or fiber lasers that are dispersed to produce super-continuum light and swept source lasers, and ii) superluminescent diodes. Highly non-linear air-silica microstructure fibers and photonic crystal fibers (PCFs) can generate an extremely broadband continuous light 
spectrum from the visible to the near infrared by use of low-energy femtosecond pulses (Wang et al, 2003; Hartl et al, 2011). Spectral bandwidth up to $372 \mathrm{~nm}$ was achieved at $1.1 \mu \mathrm{m}$ central wavelength. The super-continuum light source also has the advantage of achieving faster imaging speed with higher signal-to-noise ratio.

Although the reported OCT tomograms with the highest axial resolution $(1.8 \mu \mathrm{m})$ were so far achieved in research laboratories with a photonic crystal fibre based source (Wang et al, 2003), superluminescent diodes are considerably lower in cost and complexity as well as being smaller in size, which makes them more attractive for mass production. Superluminescent diodes utilizing quantum-dots in the active region are considered to be an excellent candidate as a light source for an OCT system. The naturally wide dimensional fluctuations of the self-assembled quantum dots, grown by the Stranski-Krastanow mode, are very beneficial for broadening the gain spectra which enhances the spectral width of the SLDs. On the other hand, the three-dimensional carrier confinement provided by the dots' shape results in high radiative efficiency required for the OCT applications.

\section{Reported superluminescent diodes for bandwidth widening and their performance parameters}

Since the first report in 1993 (Leonard et al, 1993), the formation of strained self-assembled quantum dots by heteroepitaxial growth in the Stranski-Krastanow mode has been studied extensively for their fundamental properties and applications in optoelectronics. Significant breakthroughs occurred over the last two decades with the fundamental understanding of the QDs systems and the demonstration of zero-dimensional novel devices. These achievements are directly related to the noticeable advances in the epitaxial materials deposition. With self-assembled QDs growth process, a certain size inhomogeneity is common and typically not less than $10 \%$. It has been predicted (Sun \& Ding, 1999) that the full width at half maximum of the SLDs output spectrum of the $\operatorname{In}_{0.7} \mathrm{Ga}_{0.3} \mathrm{As} / \mathrm{GaAs}$ quantum dot system, with a standard deviation in the average size of the QD ensemble of $10 \%$, can be as high as $140 \mathrm{~nm}$. Increasing further the size variation of the dots to $30 \%$ should result in bandwidth as high as $160 \mathrm{~nm}$. The confinement potential between the dots and the barriers is another important factor for modifying the spectral width. With only $10 \%$ size variation increasing the potential confinement by using higher indium composition in the dots a spectral width of $230 \mathrm{~nm}$ was predicted in the $\mathrm{In}_{0.9} \mathrm{Ga}_{0.1} \mathrm{As} / \mathrm{GaAs}$ quantum dot system (Sun \& Ding, 1999). In general, such inhomogeneous size distribution of self-assembled QDs in the active region is disadvantageous for achieving lasing of QD-lasers. However, for the designed wide spectrum QD-SLDs it becomes an effective intrinsic advantage for broadening the emission spectrum. Experimentally, using five layers of InAs/GaAs QDs grown under identical growth conditions in a molecular beam epitaxy system (Liu et al., 2005), SLDs with full width at half maximum of $\sim 110 \mathrm{~nm}$ at a central wavelength of $1.1 \mu \mathrm{m}$ have been made. For high resolution optical coherence tomography applications around $1060 \mathrm{~nm}$ an even wider broadband spectrum is required. Increasing further the bandwidth of the emission spectrum of the SLDs is a complicated process and requires more than just optimization of the growth conditions of the active region of the device. The precise control of the average size distribution of the dots within one layer is a very challenging process and is very difficult to reproduce. Very practical and successful ideas based on engineering the matrix surrounding the QDs have been also proposed and applied to the fabrication of 
broadband superluminescent diodes with central wavelength around 1060nm (Li et al, 2005; Ray et al., 2006; Yoo et al, 2007; Lv et al, 2008). Figure 2 shows examples of engineered energy band diagrams of the active region of QD-SLDs for increasing their spectral width.

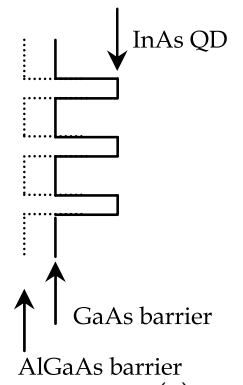

(a)

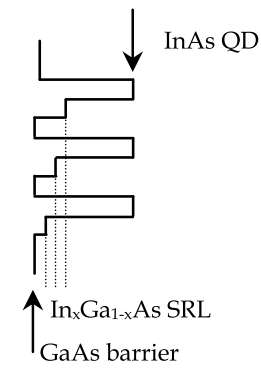

(b)

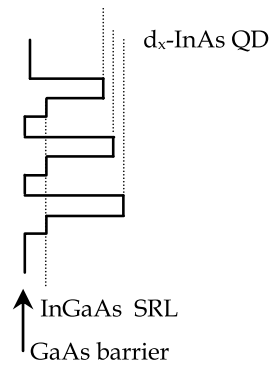

(c)

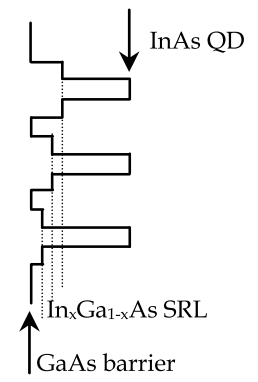

(d)

Fig. 2. Schematic band diagrams of some proposed schemes that have been reported in the literature: a) AlGaAs barrier instead of GaAs b) chirped QD structure with $\operatorname{In}_{x} G_{1-x}$ As strainreducing layer (SRL), c) chirped QD structure with InGaAs SRL and InAs dots of different size by deposition of different InAs thicknesses, d) QD structure with dots in compositionally modulated quantum wells (DCMWELL).

The use of InAs QDs in $\mathrm{Al}_{0.14} \mathrm{Ga}_{0.86} \mathrm{As}$ matrix instead of GaAs [fig.2 (a)] significantly affects the dot size and distribution and results in a light emitting diode with a spectral bandwidth of $142 \mathrm{~nm}$ (Lv et al, 2008). The introduction of aluminum atoms reduces the migration length of the indium atoms on the AlGaAs surface. This results in an increase of the nucleation centers which favors the formation of smaller dots with higher density and of larger size fluctuation. For SLDs made using such approach, output power under pulsed conditions was $3 \mathrm{~mW}$ at $4 \mathrm{~A}$ driving current.

Another effective approach for changing the matrix surrounding the QDs was reported by $\mathrm{Li}$ and co-authors (Li et al, 2005). They have introduced a thin capping $\operatorname{In}_{x} \mathrm{Ga}_{1-\mathrm{x}} \mathrm{As}$ strainreducing layer (SRL) where the indium composition was increased from $9 \%$ to $15 \%$ by an interval of $1.5 \%$ for the five layers of InAs dots of the device [fig. 2 (b)]. QD-SLDs with $121 \mathrm{~nm}$ bandwidth were demonstrated. The use of $\operatorname{In}_{x} \mathrm{Ga}_{1-x} \mathrm{As}$ SLR however red-shifted the central wavelength to $1165-1286 \mathrm{~nm}$ range. The maximum achieved output power in these devices was limited to only $1.5 \mathrm{~mW}$ in pulsed mode.

Introducing an $\mathrm{In}_{0.15} \mathrm{Ga}_{0.85}$ As SRL for all layers of dots, and changing the dots size from one layer to another by depositing different InAs thicknesses [fig. 2 (c)], is another approach that was proposed by Yoo et al. for broadening the gain spectrum of the QD-SLDs (Yoo et al, 2007). The resulted power spectrum was up to $98 \mathrm{~nm}$ wide centered at $\sim 1150 \mathrm{~nm}$. Output power of $32 \mathrm{~mW}$ in continuous-wave operation mode was measured in these devices at $900 \mathrm{~mA}$ injection current.

To control the bandwidth of the emission spectrum of QD-SLDs Ray and co-workers (Ray et al., 2006; Ray et al., 2007) proposed to use a dot in compositionally modulated well (DCMWELL) structure of different indium compositions within each well [fig. 2 (d)]. The indium compositions in this structure were chosen such that the separation of the peak 
wavelengths resulting from a dot-in-well (DWELL) of different compositions is equal to the linewidth of the individual DWELLs. Flat-topped spectral profile of 95nm full-width at halfmaximum centered at $1270 \mathrm{~nm}$ was demonstrated. The corresponding achieved output power in continuous-wave mode was $8 \mathrm{~mW}$ at $900 \mathrm{~mA}$ injection current.

Engineering the energy diagram of the surrounding matrix of the QDs is a precise and reproducible technique to manipulate the ground-state (GS) and the excited-states (ESs) peak positions for broadening the spectrum gain. Another powerful approach is to use external means to manipulate to peak positions of the GS and ESs of the dot. This was achieved by using multi-section ridge waveguide QD-SLDs. The multi-section SLDs consists of single ridge waveguide divided into three electrically isolated sections: the absorber (reverse-biased to eliminate back reflections) and the two gain sections that are independently biased at different current to favor either GS or ES emission from each section. In this configuration, adjusting the current densities and the lengths of the two SLD sections allows a control of the power output and bandwidth related to the GS and ES of the dots. Using such an approach, Xin and co-authors (Xin et al, 2007) were the first to use a multiple section QD-SLDs as a flexible device geometry that permits independent adjustment of the power and spectral bandwidth in the ground-state and the excited-states of the QDs. Emission spectrum with full width at half maximum of $164 \mathrm{~nm}$ and $220 \mathrm{~nm}$ were achieved with central wavelength of $1.15 \mu \mathrm{m}$ and $1.2 \mu \mathrm{m}$, respectively. The maximum achievable output power in continuous-wave mode, at these wavelengths, was about $0.6 \mathrm{~mW}$ and $0.15 \mathrm{~mW}$, respectively.

For fabrication of broadband SLDs around 1060nm, optimized postgrowth rapid thermal annealing at $750^{\circ} \mathrm{C}$ was also reported (Zhang et al, 2008). Compared to the as-grown structure, the bandwidth of the device was increased by a factor of two (to $146 \mathrm{~nm}$ ) with the central emission peak blueshift of 54nm (from 1038nm down to 984nm). However, this bandwidth increase was obtained at the expense of continuous-wave output power which decreased by a factor of six, down to $15 \mathrm{~mW}$.

A bipolar cascade SLD that uses tunneling junctions between distinct multiple quantum wells was also reported by Guol and co-authors (Guol et al, 2009) for bandwidth engineering. Emitting device with spectral bandwidth of $180 \mathrm{~nm}$ at central wavelength of $1.04 \mu \mathrm{m}$ was demonstrated. The corresponding maximum continuous-wave output power was $0.65 \mathrm{~mW}$.

\section{Spectral broadening using height engineered InAs/GaAs quantum dots}

Tuning the emission properties of QDs assemblies by in-situ annealing after changing the growth kinetics during the capping (Garcia et al, 1998, Wang et al, 2006), or by post-growth annealing under a GaAs (Leon et al, 1996; Kosogov et al, 1996; Babinski et al, 2001) or $\mathrm{SiO}_{2}$ proximity cap (Malik et al, 1997; Xu et al, 1998; Yang et al, 2007) have been extensively reported. At the National Research Council of Canada (NRC), we have previously reported (Wasilewski et al, 1999; Fafard et al, 1999) a growth technique, called indium-flush, to control the size and exciton levels of the self-assembled QDs. The indium-flush process consists in removing all surface resident indium at a certain position during the overgrowth of the GaAs cap layer. Using this process an additional degree of size and shape engineering, giving a much improved uniformity of the macroscopic ensemble of QDs with well-defined 
electron shells, was achieved. The process was also proven to be a very reproducible growth technique for improving the uniformity of the dots size distribution of QD ensembles in laser structures. In this chapter we will demonstrate that using the indium-flush process, to intentionally and precisely tune the GS peak position of dots from one layer to another in a superluminescent diode structure, is a controllable and effective approach to fabricate broadband emission spectra for ultrahigh resolution OCT applications (Haffouz et al, 2009; Haffouz et al, 2010; Haffouz et al, 2012).

\subsection{The epitaxial growth procedure}

The epitaxial growth of the InAs/GaAs QDs was carried out in a V80H VG molecular beam epitaxy (MBE) system using an As2 molecular flux with arsenic pressure of $\sim 1 \mathrm{e}-7$ Torr. Solid source effusion cells were used for Ga and In elements. All the growths were done using a substrate rotation of 3 s per turn to obtain uniformity throughout the wafers. The surface temperature was monitored by optical pyrometer. GaAs (100) substrate has been used as a template. Before introduction in the growth chamber, the GaAs substrates were outgassed under vacuum at $450^{\circ} \mathrm{C}$ for $2 \mathrm{~h}$. Oxide removal was carried out in-situ by either a thermal desorption process in the presence of As flux at high temperature or by first applying Ga pulses in the presence of As, partial removal of the oxide at lower temperatures via conversion of the stable $\mathrm{Ga}_{2} \mathrm{O}_{3}$ surface oxide into a volatile $\mathrm{Ga}_{2} \mathrm{O}$ oxide, and then the high temperature standard oxide removal (Wasilewski et al, 2004). The later oxide removal technique was found to reduce the substrate surface roughness. The self-assembled InAs/GaAs QD layers were obtained using the spontaneous island formation at the initial stages of the Stranski-Krastanow growth mode during the epitaxy of highly strained InAs on GaAs. The growth rates of the GaAs and InAs used in these studies were $2 \AA / s$ and $0.23 \AA$ /s, respectively. The epitaxial growth procedure of the InAs QDs on GaAs buffer was performed as following: after growing the $200 \mathrm{~nm} \mathrm{GaAs}$ buffer layer at $600^{\circ} \mathrm{C}$, the substrate

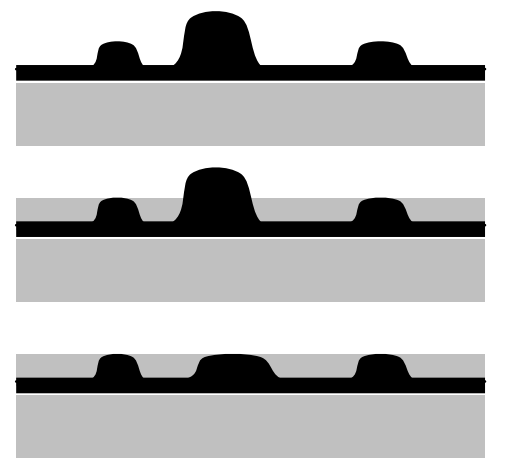

(a)

(b)

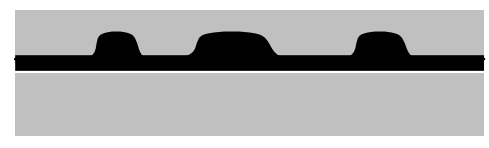

(d)

Fig. 3. Schematic drawing of the evolution of the dots during the overgrowth of the InAs with GaAs capping layer. 
temperature was lowered to $480-505^{\circ} \mathrm{C}$ where an InAs layer of $1.95-\mathrm{ML}$ thick was grown. Transition from streaky to spotty pattern measured by reflection high energy electron diffraction technique, which indicates the onset of the dot formation, was observed after approximately 26s of indium deposition [Fig. 3(a)]. A short anneal for $30 \mathrm{~s}$ at the same substrate temperature followed by a partial capping of the formed dots by a GaAs layer was applied [Fig. 3(b)]. The thickness of the GaAs layer in this case was varied in the range of 2.5 - to $6.5-\mathrm{nm}$ thick, thicknesses that are well below the typical average dots height $(\geq 10 \mathrm{~nm})$. Right after the partial capping of the dots, the indium-flush was executed by interrupting the growth, raising rapidly the substrate temperature to $610^{\circ} \mathrm{C}$ and annealing for $70 \mathrm{~s}$ at that temperature. During this step, In/Ga interdiffusion was taking place and the non-protected resident indium desorbed [Fig. 3(c)]. The substrate temperature was then reduced to $600^{\circ} \mathrm{C}$ to complete the capping of the formed disk-like dots by growing a GaAs layer of total thickness of 100nm (Fig. 3(d)). For morphological analysis of the QDs, extra layer of dots (surface dots) was grown above the GaAs capping layer and left uncapped.

\subsection{Tuning InAs quantum dots for high areal density}

Epitaxial growth of InAs QD layers of high areal dot density and good optical quality is required to fabricate high optical gain devices like lasers, SLDs, SOAs, etc. Particularly, for broadband emission SLDs, high areal dot density should improve the optical properties of the QD-SLDs, since, unlike QD lasers, emission from QD-SLDs is contributed by QDs of all sizes. Size inhomogeneity in QD layers of low density is small compared to QD layers of high density. Therefore, the use of high areal dot density should introduce a wider emission energy range.

Fig.4 shows atomic force microscope (AFM) images of surface dots grown under identical growth conditions but different substrate temperature for the deposition of the InAs layer. In these QD layers, the indium-flush of the buried layers was executed after partial capping of the QDs with GaAs of $4.5 \mathrm{~nm}$ thickness. When the InAs layer was deposited at substrate temperature of $505^{\circ} \mathrm{C}$ [fig. $4(\mathrm{a})$ ] an areal dots density of $1.4 \times 10^{10} \mathrm{~cm}^{-2}$ was obtained. Decreasing the deposition temperature of the InAs layer to $480^{\circ} \mathrm{C}$ [fig. 4 (b)] reduces the adatom migration length which led to the formation of new nucleation sites for the impinging adatoms, reducing the combination/coalescence with the existing dots. This resulted in the formation of denser dots with larger size inhomogeneity. The achieved areal dot density was about $1 \times 10^{11} \mathrm{~cm}^{-2}$.
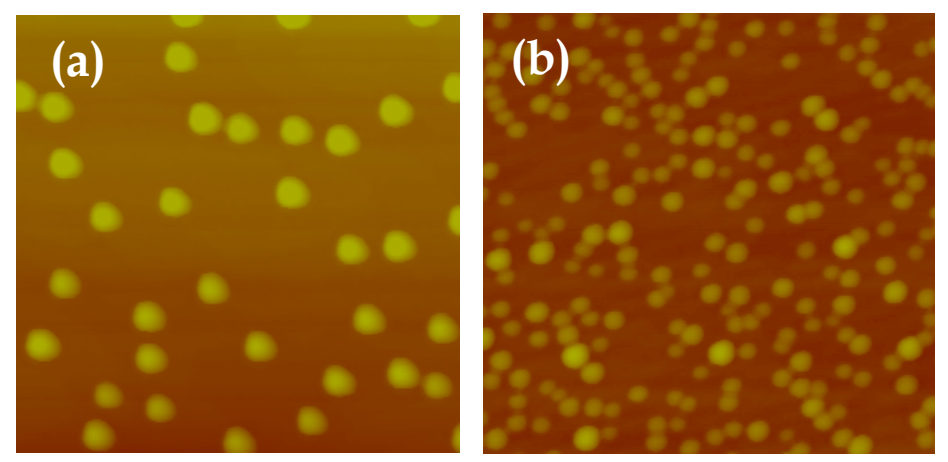

Fig. 4. Atomic Force Microscope (AFM) images of surface InAs QDs on GaAs buffer deposited at a substrate temperature of $505^{\circ} \mathrm{C}(\mathrm{a})$ and $480^{\circ} \mathrm{C}(\mathrm{b})$. The surface area is $500 \mathrm{~nm} \times 500 \mathrm{~nm}$. 
Fig. 5 shows the optical properties as measured by photoluminescence (PL) at 77K of a single layer of InAs QDs grown at different substrate temperatures. The samples $S_{1}, S_{2}, S_{3}$ and $S_{4}$ correspond to growth temperatures of $505,495,485$ and $480^{\circ} \mathrm{C}$, respectively. With identical monolayer coverage (1.95ML of InAs), the areal dot density can be directly controlled by the substrate temperature to achieve a dots density as high as $\sim 1 \times 10^{11} \mathrm{~cm}^{-2}$. At high growth temperature $\left(\mathrm{S}_{1}\right)$, PL spectra with a ground-state (GS) peak position at $1.185 \mathrm{eV}$ and with wellresolved excited states peaks $(n=1,2,3,4)$ were obtained. Increasing further the dots density $\left(\mathrm{S}_{2}\right)$, the GS peak position remained unchanged (at $\left.1.187 \mathrm{eV}\right)$, however the number of the excited-state transition peaks reduced $(n=1,2,3)$. The measured intersublevel energy spacing was about $57 \mathrm{meV}$ for both samples. No noticeable change in the PL intensity was measured between $S_{1}$ and $S_{2}$. However, increasing the dot density to $6 \times 10^{10} \mathrm{~cm}^{-2}$ significantly changed the PL spectrum which is now consisted in a single wideband centred at $1.222 \mathrm{eV}$ with a slightly reduced intensity. In sample $S_{4}$, where the dot density reached $\sim 1 \times 10^{11} \mathrm{~cm}^{-2}$, the PL intensity was significantly reduced (by a factor of 100) and the central peak was blueshifted by $31 \mathrm{meV}$. The spectra broadening in the case of $S_{3}$ and $S_{4}$ can be explained by the lateral coupling between the dots, the GS emission from the small dots overlapping with the emission from larger dots. However, the noticeable reduction in the PL intensity in $S_{4}$ was related to the formation of defective dots when their density was increased. For broadband SLDs fabrication, a compromise between high dot density and good optical properties had to be taken into account. For SLD fabrication an areal dot density of about $4-5 \times 10^{10} \mathrm{~cm}^{-2}$ was chosen, using a growth temperature for the InAs layer of around $490^{\circ} \mathrm{C}$.

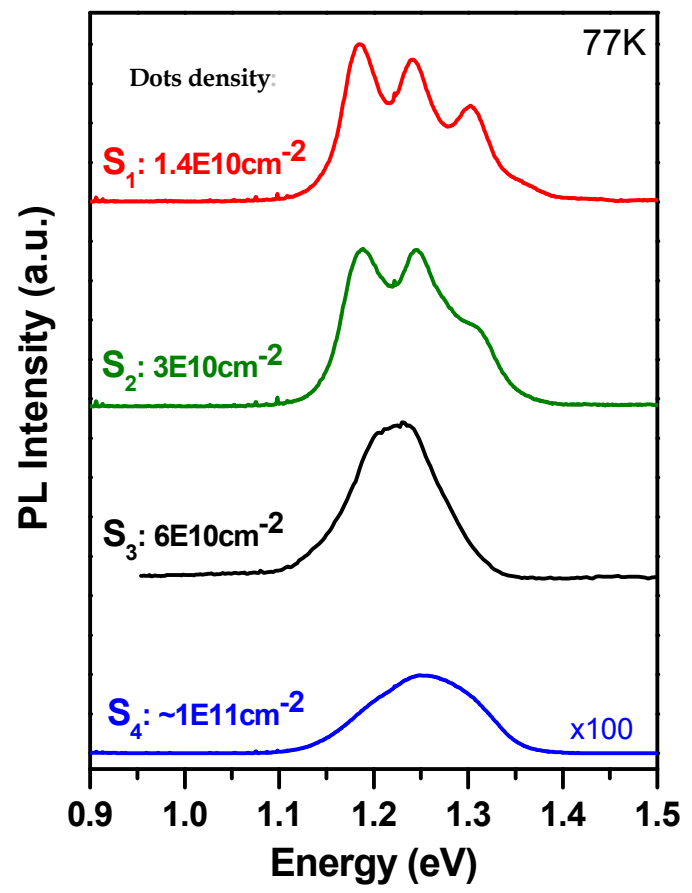

Fig. 5. Photoluminescence spectra measured at 77K of single layers of InAs QDs of different areal densities, capped with 100nm GaAs layers. 


\subsection{Height engineering of self-assembled InAs/GaAs QDs for wideband emission}

The indium-flush process is a very reproducible and predictable process to engineer the QD height and is therefore a reliable tool for tuning the QD emission energy. By varying the thickness of the GaAs cap layer at which the indium-flush process is executed, the groundstate transition energy of the QDs can continuously be adjusted over a wide emission wavelength range. Combining selected layers of QDs with various dot heights offers the possibility to reliably broaden the emission bandwidth of the QD-SLD spectrum. With this motivation, we have carried out a study on tuning the dot height by growing a single layer of dots where the indium flux process was executed at different $\mathrm{GaAs}$ partial capping thickness. For all the samples a buffer layer of $200 \mathrm{~nm}$ of GaAs was first deposited at $600^{\circ} \mathrm{C}$ on an undoped GaAs (100) substrate before the growth of the InAs layer at a temperature of $490^{\circ} \mathrm{C}$.
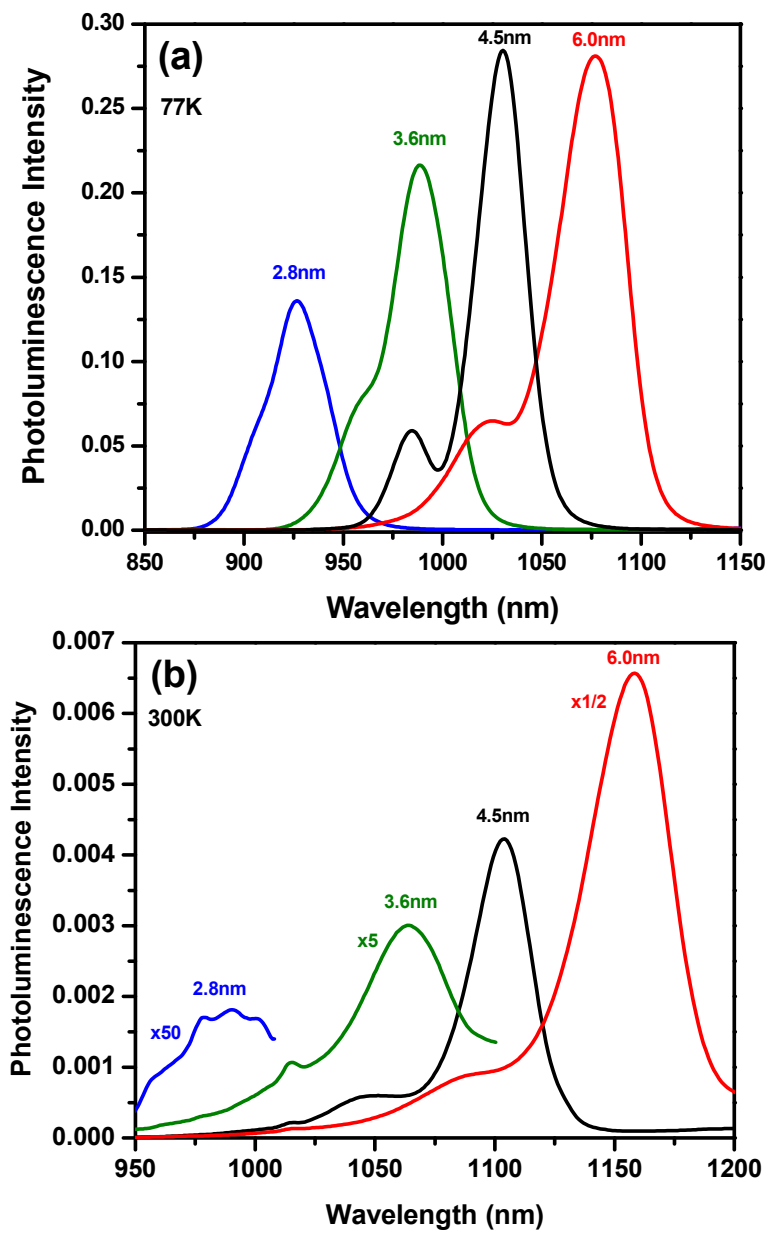

Fig. 6. Photoluminescence spectra at 77K (a) and at room-temperature (b) of single layers of InAs QDs grown with the indium-flush process that was executed at different thicknesses of GaAs capping layer. 
Fig. 6(a) and (b) show the photoluminescence spectrum, measured respectively at $77 \mathrm{~K}$ and at room-temperature, of a single layer of dots where the indium flux process was executed after the deposition of a thin GaAs cap layer between 2.8 and $6.0 \mathrm{~nm}$ of thicknesses. The areal dot density in these layers was in the range of $3-4 \times 10^{10} \mathrm{~cm}^{-2}$. Due to the high areal dot density, only the first intersublevel energy transition (s-shell) is observed. It should be noticed that decreasing the average dot height within one layer reduced the photoluminescence emission intensity very quickly at room-temperature whereas the decrease of the photoluminescence intensity was less pronounced at $77 \mathrm{~K}$. The photoluminescence intensity drop from one layer of dots to another at room-temperature can be explained by the reduction in the carrier confinement due to the reduced potential barrier for carriers in smaller dots. However, with suppressed non-radiative recombination at $77 \mathrm{~K}$, due to the reduced mobility of carriers at lower temperatures, the photoluminescence intensity drop from one sample to another was reduced. Nevertheless, PL intensity reduction at $77 \mathrm{~K}$ by $\sim 50 \%$ can still be observed in the layer of shorter dots as compared to longer ones.

Fig. 7 shows the variation of the GS and the first ES emission wavelength values at roomtemperature and at $77 \mathrm{~K}$ for the grown layer of dots as a function of the average dot height. From previous transmission electron microscopy studies (Haffouz et al, 2009), we found that the average dot height within one layer is approximately the thickness of the GaAs layer deposited at low temperature minus $2 \mathrm{~nm}$. With increasing dot height, by increasing the thickness of the deposited GaAs cap layer at low temperature before the indium-flush process, the GS peak wavelength of the emission spectrum shifted towards longer wavelength by about $150 \mathrm{~nm}$ and $169 \mathrm{~nm}$ at $77 \mathrm{~K}$ and $300 \mathrm{~K}$, respectively. Combining these four layers of dots in the active region of a superluminescent diode could be very beneficial in generating a broadband emission spectrum.

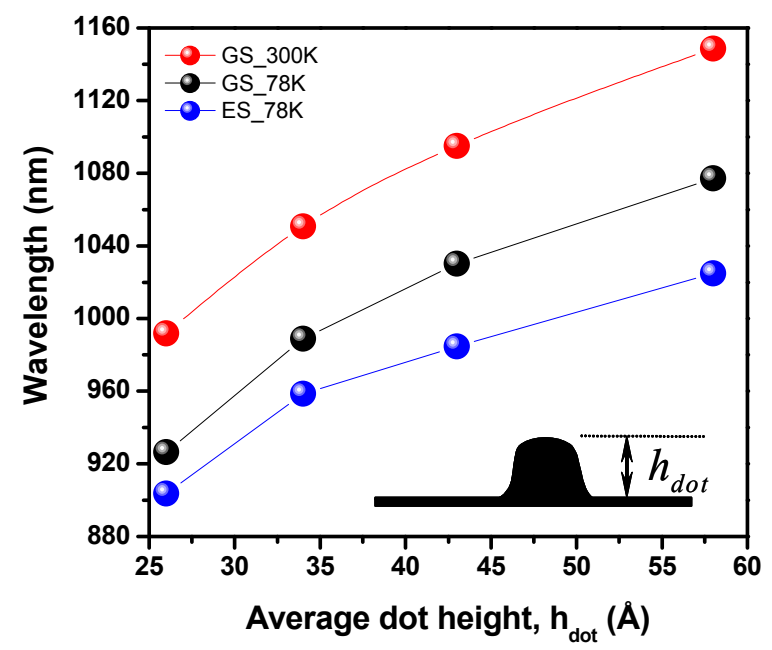

Fig. 7. Variation of the GS and ES peak wavelengths as extracted from the photoluminescence spectra as a function of average dot height. 


\section{Ultra wide bandwidth SLDs using InAs QDs of tuned heights: Epitaxial growth, fabrication and testing}

Tuning the QD emission energy levels by varying the thickness of the GaAs cap layer (from $2.5 \mathrm{~nm}$ to $6.5 \mathrm{~nm}$ ) at which the indium-flush process is executed, the ground-state emission wavelength peak position at $300 \mathrm{~K}$ can be precisely adjusted from $990 \mathrm{~nm}$ to $1150 \mathrm{~nm}$ (Haffouz et al, 2009; Haffouz et al, 2012). Therefore, combining selected layers of QDs with various dots heights offers the possibility to reliably broaden the emission bandwidth of the QD-SLD spectrum. Demonstration of symmetric and regular shape emission spectra is required in order to avoid the presence of sidelobes in the OCT interferogram which could be a potential source of spurious structures in the OCT images. To maximize the bandwidth of the emission spectrum of the device, and in order to avoid the formation of dips in the power spectrum, the GS separation energy between adjacent layers of dots should be carefully tuned. We have chosen four different heights of dots in such a way that there was an overlap between the GS emission line from one layer of dots and the ES from the adjacent layer. The chosen average heights of the dots in each layer were about $2.6 \mathrm{~nm}, 3.4 \mathrm{~nm}, 4.8 \mathrm{~nm}$ and $5.8 \mathrm{~nm}$. The dot layers were grown in such a way that the dot height was gradually increased from $2.6 \mathrm{~nm}$ up to $5.8 \mathrm{~nm}$ starting from the bottom to top in the epitaxial device structure (described in the paragraph hereafter).

The device structure was grown on an n+-GaAs (100) substrate in a solid-source V80H VG molecular beam epitaxy system. To achieve the $1 \mu \mathrm{m}$ emission line, InAs QDs inside a GaAs matrix have been grown. The InAs material growth temperature and growth rate were $490^{\circ} \mathrm{C}$ and $0.023 \mathrm{~nm} / \mathrm{s}$, respectively. The obtained dots density was $\sim 5 \times 10^{10} \mathrm{dots} / \mathrm{cm}^{2}$. The active region of the device consisted in two repeats of four layers of InAs quantum dots with GaAs barrier/cap layers, within a $300 \mathrm{~nm}$ thick waveguide. 200nm-thick graded index $\mathrm{Al}_{\mathrm{x}} \mathrm{Ga}_{1-\mathrm{x}} \mathrm{As}\left(\mathrm{x}=0.1-0.33\right.$ ) layer was grown at $600^{\circ} \mathrm{C}$ around the QD core with a $1.5 \mu \mathrm{m}$ $\mathrm{Al}_{0.33} \mathrm{Ga}_{0.67} \mathrm{As}$ :Be $\left(1 \times 10^{18} \mathrm{~cm}^{-3}\right)$ upper cladding and a $1.5 \mu \mathrm{m} \mathrm{Al}_{0.33} \mathrm{Ga}_{0.67} \mathrm{As}: \mathrm{Si}\left(2 \times 10^{18} \mathrm{~cm}^{-3}\right)$ lower cladding layer. After each $97 \mathrm{~nm}$ of n-cladding growth, a $3 \mathrm{~nm}$ GaAs:Si layer was grown to smooth the surface. The top $100 \mathrm{~nm}$ GaAs:Be contact layer was doped to a level of $2 \times 10^{19} \mathrm{~cm}^{-3}$, while the bottom GaAs:Si buffer layer was doped to $2 \times 10^{18} \mathrm{~cm}^{-3}$.

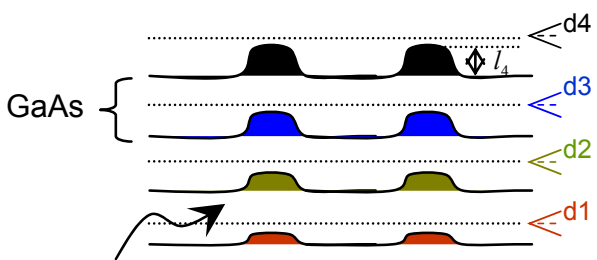

InAs QDs

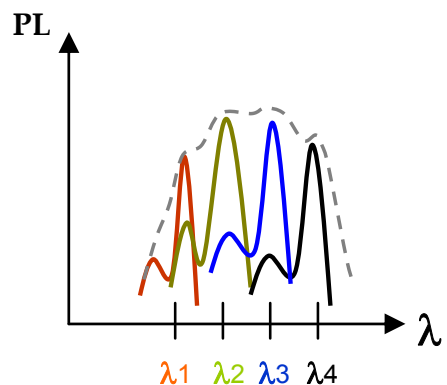

(b)

Fig. 8. (a) Schematic structure of the active region of the SLDs where the dot height was varied by controlling the thickness of the GaAs cap layers deposited at low temperature. The arrows indicate the position where the indium-flush was executed $\left(\mathrm{d}_{\mathrm{x}}\right) \cdot \mathrm{l}_{4}$ is the height of the dots in layer 4. (b) Schematic diagram of the photoluminescence (PL) spectrum of such a stack of quantum dots. 
Figure 8(a) shows a schematic drawing of the active region of the SLDs used in this study. The four layers of InAs QDs were grown using the same amount of InAs materials (1.95 ML), whereas the indium-flush was executed respectively at thicknesses equal to $2.8 \mathrm{~nm}, 3.6 \mathrm{~nm}, 4.5 \mathrm{~nm}$ and $6.5 \mathrm{~nm}$ from bottom to top layers. This resulted in the formation of truncated dots with their height typically about $2 \mathrm{~nm}$ smaller than the corresponding indium-flush position. The predicted photoluminescence spectrum is an overlap of four spectra, each of which having a ground-state transition energy position inversely proportional to the average of the dots height in its corresponding layer [Fig. 8(b)].
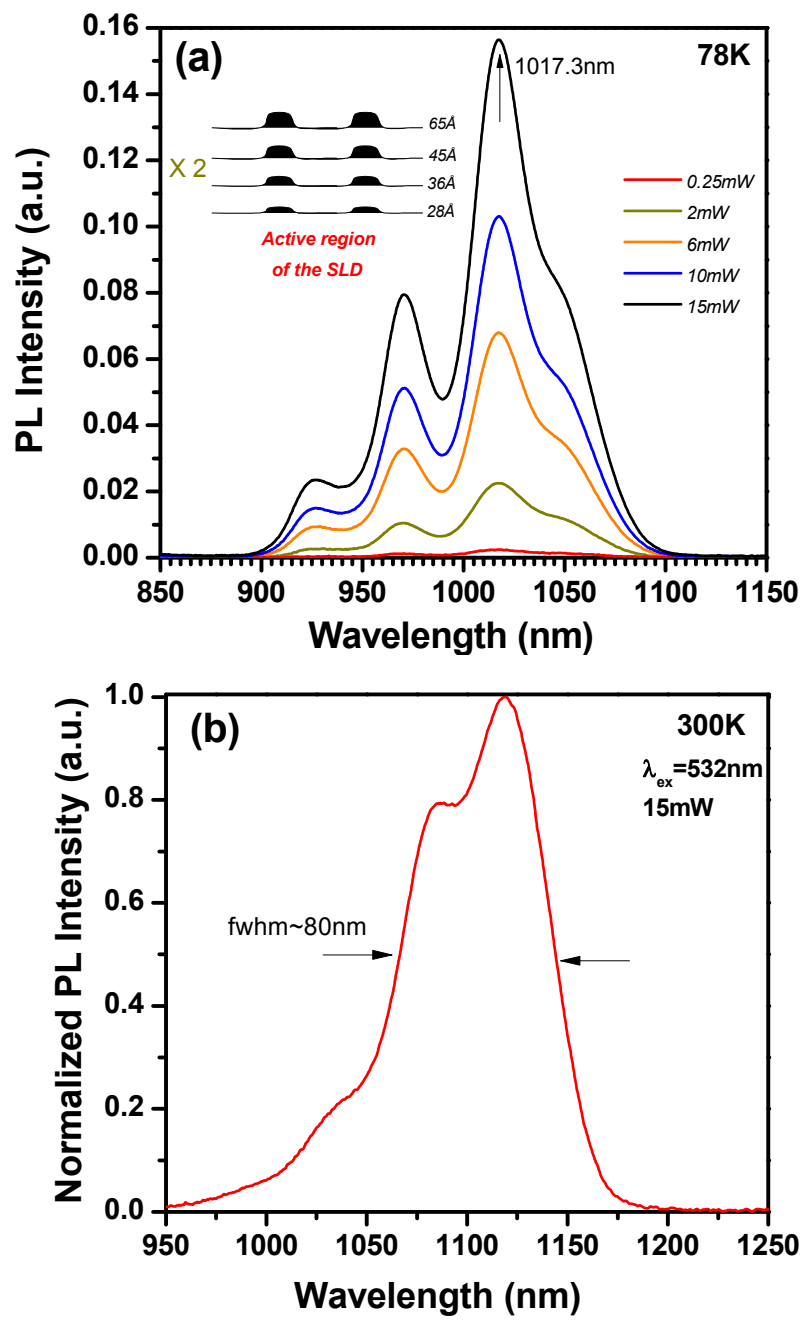

Fig. 9. Photoluminescence spectrum at a) $78 \mathrm{~K}$ and b) room-temperature of the QD-SLD structure incorporating four layers of InAs QDs where the indium flushes were executed at different thicknesses $(2.8 \mathrm{~nm}, 3.6 \mathrm{~nm}, 4.5 \mathrm{~nm}$ and $6.5 \mathrm{~nm})$. 
Photoluminescence measurements at low temperature $(78 \mathrm{~K})$ with various excitation powers [Fig. 9(a)] and at room-temperature [Fig. 9(b)] have been carried out on this QD-SLD structure after removing the top contact layer and the AlGaAs claddings. As displayed in Fig. 9(a), the recorded photoluminescence spectra with varied excitation powers indicates that the four peaks at energy wavelengths of $926 \mathrm{~nm}, 970 \mathrm{~nm}, 1017 \mathrm{~nm}$ and $1050 \mathrm{~nm}$ corresponding to the ground-state transitions wavelengths of the layers of dots with indium-flush positions at $2.8 \mathrm{~nm}, 3.6 \mathrm{~nm}, 4.5 \mathrm{~nm}$ and $6.5 \mathrm{~nm}$, respectively. No state filling was observed with power excitation up to $15 \mathrm{~mW}$. Moreover, distinguishing the transitions related to the excited-states was render difficult by the fact that the combined layers of dots were designed in such a way that there was an overlapping between the GS emission peak from one layer of dots and the ES from the adjacent layer. Overlapping these four layers of QDs with deliberately varied heights has successfully resulted in a broad photoluminescence spectrum with a full width at half maximum of $82 \mathrm{~nm}$ and peak wavelength energy of $1.02 \mu \mathrm{m}$. Strong room-temperature photoluminescence emission [fig. 9(b)] was also observed around 1120nm with a full width at half maximum of $80 \mathrm{~nm}$. Further populating the GSs of the smaller dots, by increasing the power excitation, increased the photoluminescence emission intensity from the corresponding energy levels and considerably broadened the photoluminescence spectrum of the QDs' ensemble. A fullwidth at half-maximum of $125 \mathrm{~nm}$ was measured with excitation power of $100 \mathrm{~mW}$ (Haffouz et al, 2009).

Fig. 10 shows cross-section transmission electron microscopy images of a representative dot within each layer of the active region of the QD-SLDs. Truncated shape quantum dots were obtained from the indium-flush process. The variation in the dot height from one layer to another by varying the thickness of the GaAs layer during partial capping can be observed. This is consistent with the observation from the photoluminescence studies that the GS energy wavelength peak decreased when reducing the dot height.

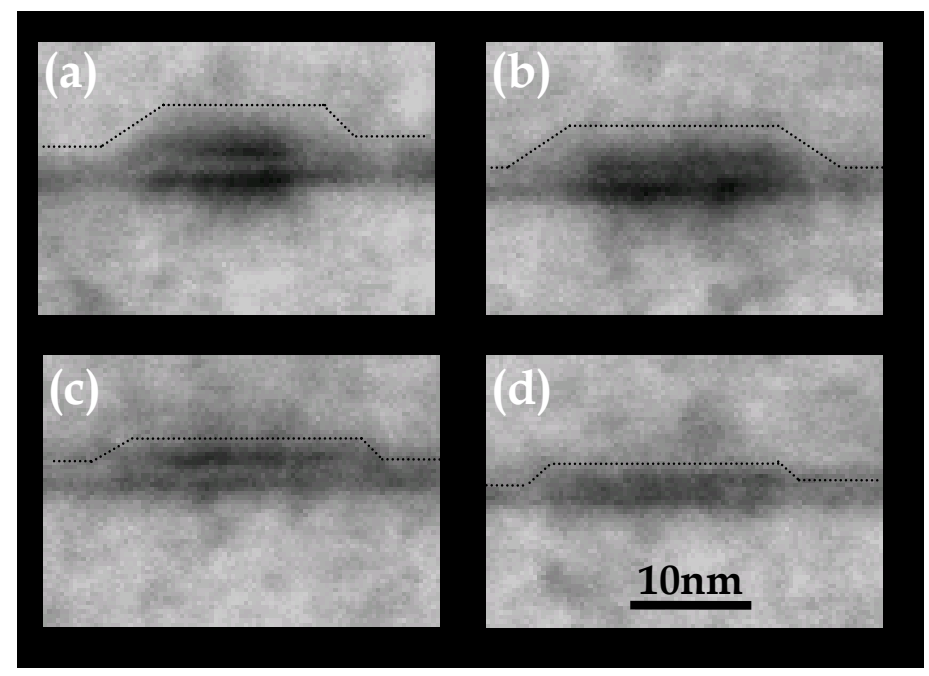

Fig. 10. Cross-section transmission electron microscopy images of representative dot from each layer where the dots height was deliberately tuned. The corresponding indium-flush positions were $6.5 \mathrm{~nm}(\mathrm{a}), 4.5 \mathrm{~nm}(\mathrm{~b}), 3.6 \mathrm{~nm}(\mathrm{c})$, and $2.8 \mathrm{~nm}(\mathrm{~d})$, respectively. 
To fabricate a superluminescent diode, a ridge waveguide tilted by $5-8^{\circ}$ off the normal facet is typically used to avoid lasing. It has been also reported (Koyama et al, 1993; Yamatoya et al, 1999) that to lower the effective reflectivity of the device facets, SLED fabricated into a tilted and tapered waveguide can be realized. Such a geometry improves the saturation output power and the quantum efficiency. A simplified schematic drawing, which we used in this study is shown in Fig.11. Devices with various tilt $(\alpha)$ and and tapered-angles $(\beta)$ were fabricated and tested. For devices of $1-2 \mathrm{~mm}$ long, the width of the emitting facets were in the range of $35.21-176.91 \mu \mathrm{m}$. The main difference between these waveguides of different sizes was reflected in the output power of the device. A deflector of $54.7^{\circ}$ made in the shape of V-grooves (Middlemast et al, 1997) by wet etch was also implemented in the fabrication process in order to avoid the reflected light to re-enter the active region by deflecting it into the substrate. Finally, an unpumped absorption region of $300 \mu \mathrm{m}$ wide was implemented at the narrow end of the tapered region just ahead the V-grooves. The devices were mounted p-side up on a Au-plated $\mathrm{Cu}$-heatsink and the cooling was set to an operation temperature of $20^{\circ} \mathrm{C}$. The devices were characterized under continueous-wave and pulsed operation conditions.

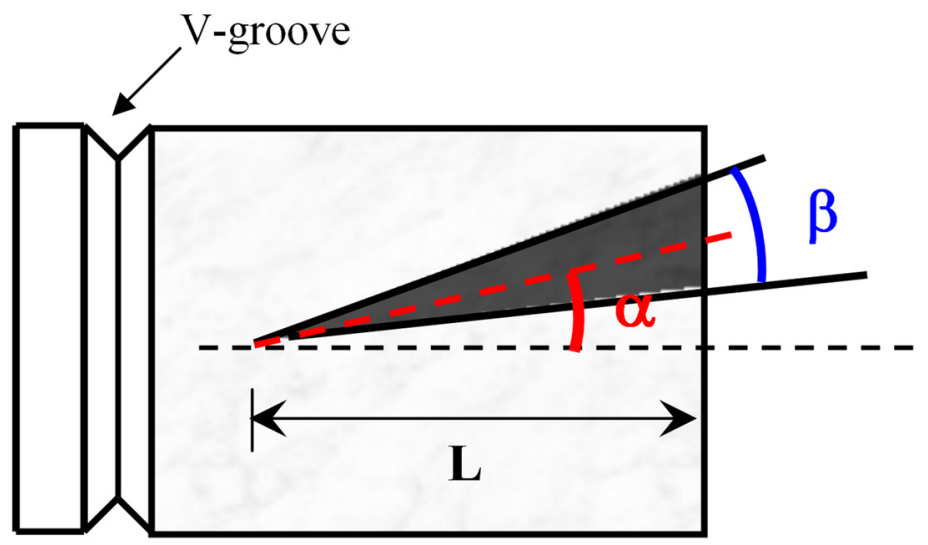

Fig. 11. Schematic drawing of the tilted and tapered waveguide design. $L$ is the length of the tapered region.

Fig. 12 displays the recorded power spectrum of the QD-SLDs at various continueous-wave drive currents. The tapered region was $1-\mathrm{mm}$ long whereas the tilt and tapered angles were $2^{\circ}$ and $8^{\circ}$, respectively. The resulted width of the output facet was $35.49 \mu \mathrm{m}$. At very low drive current $(2 \mathrm{~mA})$, a broadband emission centered at $1100 \mathrm{~nm}$ with a bandwidth of $60 \mathrm{~nm}$ was obtained. By increasing the injection current, the emission spectrum broadened further and the central wavelength blue-shifted by $\sim 80 \mathrm{~nm}$. This can be explained by the carrier transfer effects between the different dots and the energy band filling from low to high energy levels.

Fig.13 summarizes the variation of the emission spectra bandwidth and its corresponding peak wavelength as a function of the injection current. The enhancement of the $3 \mathrm{~dB}-$ bandwith and the continuous blue-shift of the corresponding peak wavelength with increasing injection current from $2 \mathrm{~mA}$ to $700 \mathrm{~mA}$ are attributed to the progressive increase of contribution of all dots to the emission mechanism. At a low injection current, the carriers 
excited in small dots, which have smaller exciton localization energies, may escape out of the dots and transfer to the large ones, and then radiate. When increasing the injection current, GS in larger dots become occupied, thus reducing the transfer of carriers between isolated dots. The energy states of small dots then begin to be filled and the shape of the emission spectrum slowly approaches that of the QDs' size distribution. With the further increase of injection current, the emission from GS of the QDs' ensemble saturates, and the carriers start to fill the ESs. Because of the ultrawide GS gain spectrum (as demonstrated in Fig. 12), the simultaneous contributions from multiple states do not change the spectral shape, but only broaden the emission bandwidth. Both effects are more beneficial for broadening the spectrum at shorter wavelengths, so that a blue-shift of emission spectra occurred simultaneously. Once all the energy levels (GS and ESs) of the different dots have been saturated, an emission spectrum fully represented by all dots' size distributions is achieved. A maximum 3dB-bandwidth of $190 \mathrm{~nm}$ was measured at $700 \mathrm{~mA}$ injection current, with a central wavelength of emission spectrum around $1020 \mathrm{~nm}$. Above $700 \mathrm{~mA}$ drive current, the central wavelength of the spectrum did not change but we noticed a narrowing of the bandwidth of the spectrum down to $160 \mathrm{~nm}$. It should be mentioned that the modulation observed in the emission spectra are likely introduced during measurement due feedback effects. We have previously noticed that applying anti-reflection coating on the emitting facet significantly reduce such modulations.

It is believed that the engineered dot height was the reason for the ultra wide bandwidths observed even at relatively low injection current. The precise control of the dots height by controlling the thickness of the GaAs cap layer offers the possibility to precisely manipulate the ground-state peak position of each layer of dots and therefore engineer the bandwidth in a controlable manner. The calculated OCT axial resolution (Eq. 3) from the achieved 3dBbandwidth of $190 \mathrm{~nm}$ at central wavelength of $1020 \mathrm{~nm}$ in our devices is about $2.4 \mu \mathrm{m}$.

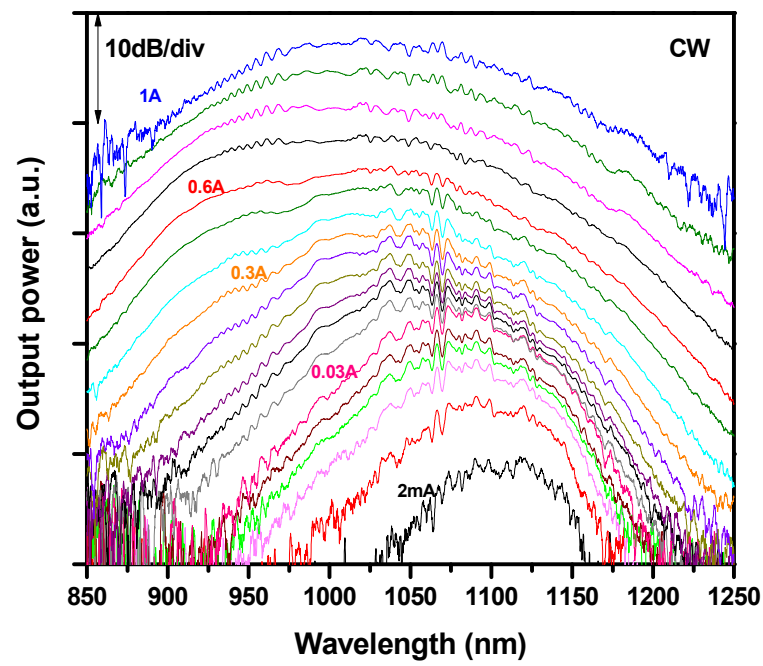

Fig. 12. Emission spectra of the fabricated device under various injection currents. The waveguide was $1 \mathrm{~mm}$ long, with tilted $(\alpha)$ and tapered $(\beta)$ angles of $8^{\circ}$ and $2^{\circ}$, respectively. 


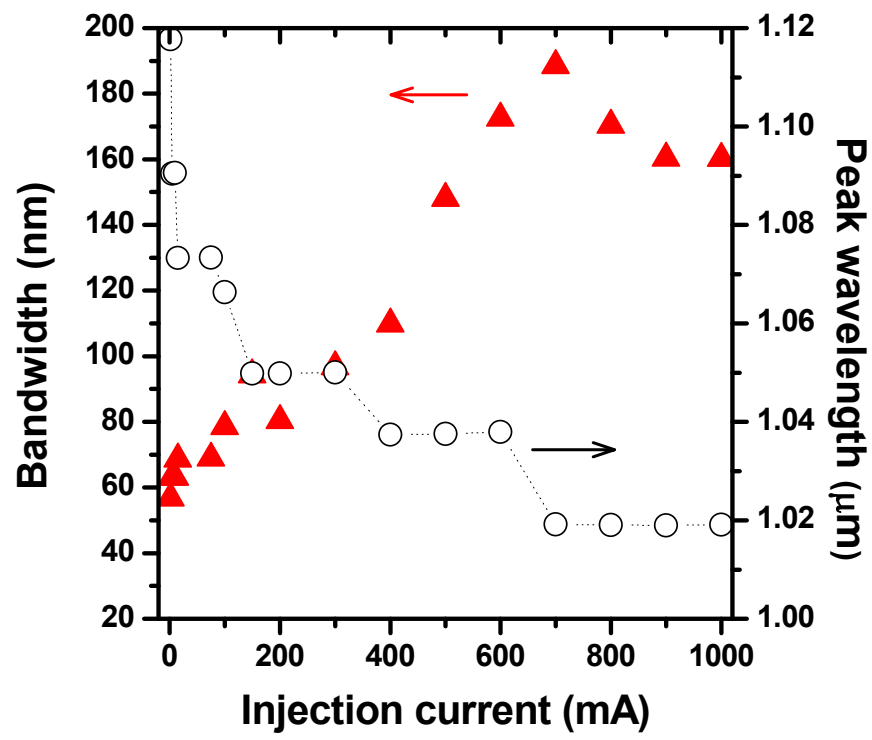

Fig. 13. Variation of the emission spectra bandwidth and its corresponding peak wavelength as a function of the injection current. The waveguide is $1 \mathrm{~mm}$ long and with tilted $(\alpha)$ and tapered $(\beta)$ angles of $8^{\circ}$ and $2^{\circ}$, respectively.

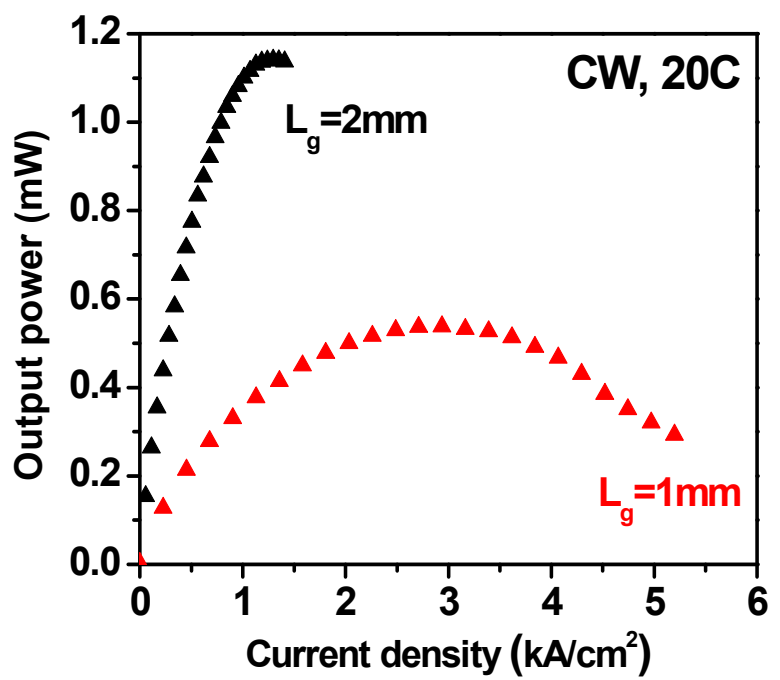

Fig. 14. Light output-injection current curves measured at $20^{\circ} \mathrm{C}$ under continuous-wave operation mode. The inset shows the schematic drawing of the tapered waveguide.

Fig. 14 shows the output power against the injection current density for $1 \mathrm{~mm}$ and $2 \mathrm{~mm}$ long devices measured at $20^{\circ} \mathrm{C}$ under continuous-wave operation conditions. A maximum output power of $0.54 \mathrm{~mW}$ under an injection current of $3 \mathrm{kA} / \mathrm{cm}^{2}$ was achieved in $1 \mathrm{~mm}$ long device. 
Above $3 \mathrm{kA} / \mathrm{cm}^{2}$, the output power decreases due to the thermal effect caused by relatively high series resistance as measured in our devices. Increasing the device length resulted in an improved performance where an output power of $1.15 \mathrm{~mW}$ was measured in $2 \mathrm{~mm}$-long device at injection current density of $1.3 \mathrm{kA} / \mathrm{cm}^{2}$. This may indicate that the single pass amplification of the spontaneous emission generated along the waveguide did take place in our devices under continuous wave operation conditions and it varies with the cavity length. However, from these L-I curves, there is no sign of the superluminescent phenomenon in our devices. The existence of the amplified spontaneous emission in our devices (that is varying with the cavity length) and the bandwidth narrowing are characteristics of an SLD but a light-emitting-diode like L-I curves were obtained under continuous wave operation mode. We believe that the super-linear behaviour in the L-I curve is "masked" by the heating problem which is causing L-I curve going down before reaching the injection current range where a super-linear behaviour would appear. To verify his, we have also tested the device of $1 \mathrm{~mm}$ long under different pulse mode operations.

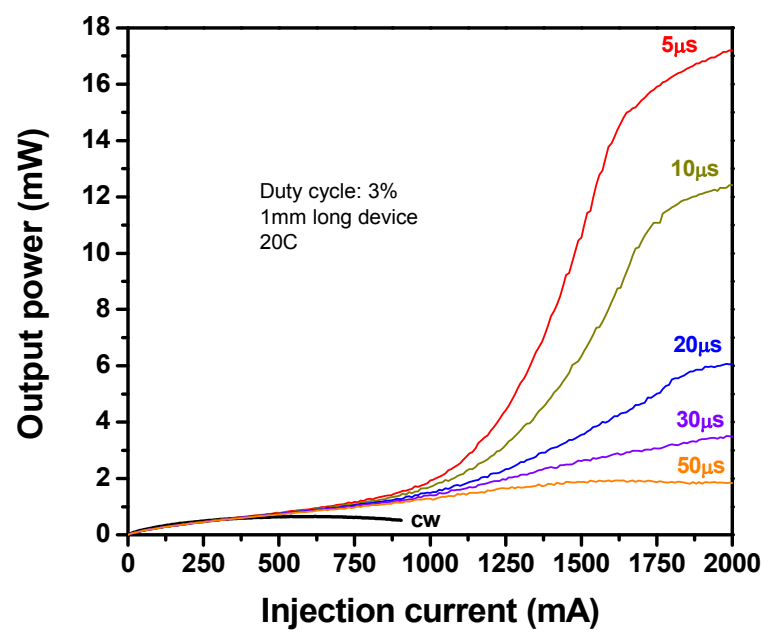

Fig. 15. Light output-injection current curve measured at $20^{\circ} \mathrm{C}$ under pulsed mode. The pulse width was varied in the range of $5-50 \mu$ s whereas the duty cycle was $3 \%$. The waveguide is $1 \mathrm{~mm}$ long and with tilted $(\alpha)$ and tapered $(\beta)$ angles of $8^{\circ}$ and $2^{\circ}$, respectively.

Fig. 15 shows the L-I curves of $1 \mathrm{~mm}$ long device measured under different pulsed operation conditions. A maximum achievable output power of $17 \mathrm{~mW}$ under an injection current of $2 \mathrm{~A}$ was measured with a pulse with of $5 \mu \mathrm{m}$ and a duty cycle of $3 \%$. The super-linear increase of the power with the injection current was observed at threshold current of about 1A. However, increasing the pulse width reduces significantly the maximum achievable output power and the superlinear phenomenon gets less pronounced for pulse with higher than $50 \mu \mathrm{s}$. As a comparison, we plotted the L-I curve under continuous wave mode together with the L-I curves measured under pulsed mode. As it can be seen, the device under continuous wave suffer from heating problems which causes the L-I curve to go-down (at $\sim 500 \mathrm{~mA}$ ) well before reaching the injection current range when the super linear phenomenon kicks-in (at $\sim 1000 \mathrm{~mA}$ ). 

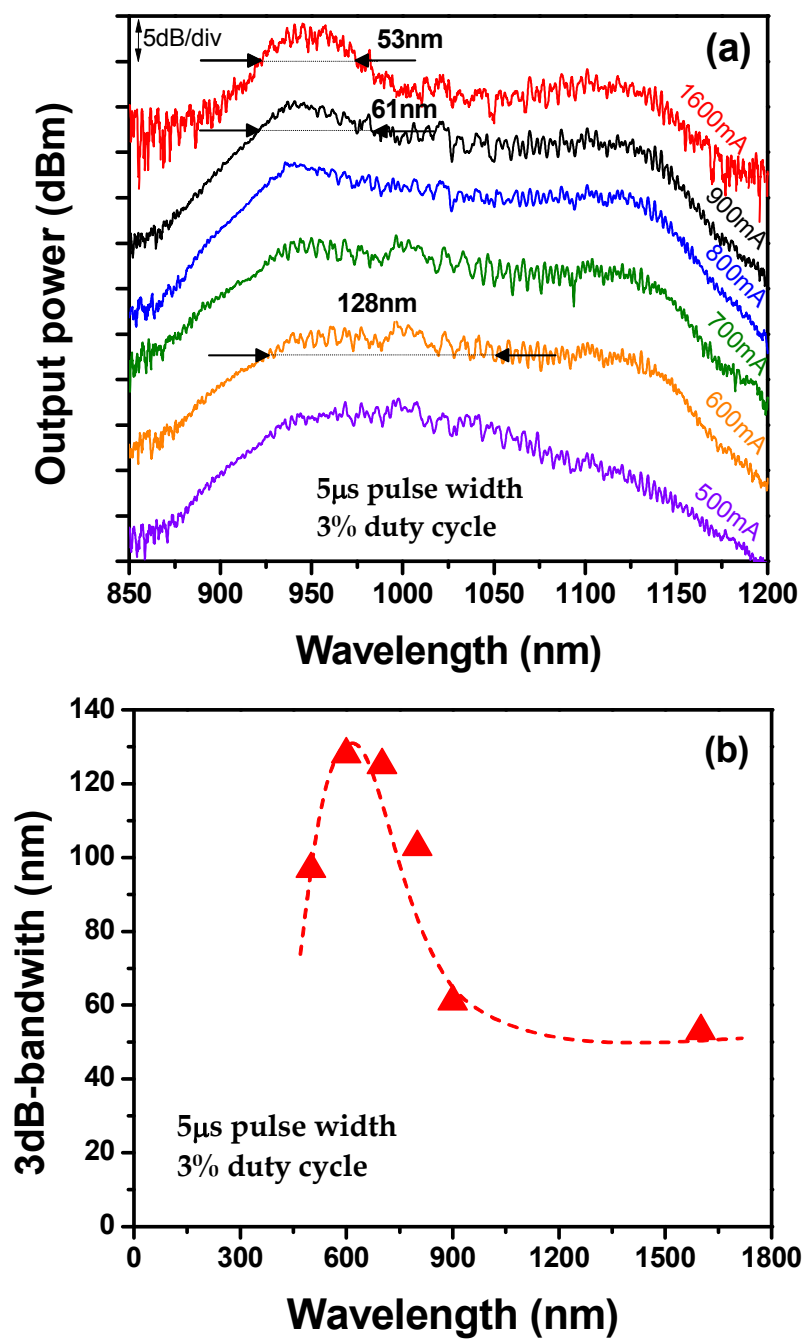

Fig. 16. a) Emission spectra of the fabricated device at different injection currents under pulse mode operation. b) Variation of the $3 \mathrm{~dB}$ bandwidth of the emission spectrum as a function of injection current. The used pulse width and duty cycle is $5 \mu$ s and $3 \%$, respectively. The waveguide is $1 \mathrm{~mm}$ long and with tilted $(\alpha)$ and tapered $(\beta)$ angles of $8^{\circ}$ and $2^{\circ}$, respectively.

Fig. 16 shows the emission spectra of the fabricated device at different injection currents under pulse mode operation [Fig. 16(a)] and its corresponding 3dB bandwidth [Fig. 16(b)]. Broadband spectrum with $3 \mathrm{~dB}$ bandwidth of $128 \mathrm{~nm}$ was measured at injection current of $600 \mathrm{~mA}$. Above this drive current, the bandwidth of the power spectrum decreases rapidly down to $53 \mathrm{~nm}$ at injection current of $1600 \mathrm{~mA}$. As it can be seen from Fig. 16(b), the bandwidth narrowing above an injection current of $700 \mathrm{~mA}$ corresponds well to the injection 
current range where the superlinear behavior was observed in L-I curves in Fig. 15. This bandwidth narrowing is caused by the disproportionate increase in gain for different wavelengths.

In summary, the largest 3dB-bandwidth measured in our devices was respectively 190nm and $128 \mathrm{~nm}$ under continuous-wave and pulse-mode operation. The corresponding output power under continuous-wave and pulse-mode operation was $0.54 \mathrm{~mW}$ and $1.2 \mathrm{~mW}$, respectively. Broadband QD-SLDs operating at central wavelength of $1.2-1.3 \mu \mathrm{m}$ with $3 \mathrm{~dB}$ bandwidth not exceeding 100nm typically can deliver an output power of few tens of milliwatts (Yoo et al, 2007, Ray et al, 2007). However, for SLDs with much broader bandwidths (wider than 150nm), the amplified spontaneous emission level is reduced resulting in lower output power (Xin et al, 2007; Guol et al, 2009). For increasing the output power in extremely broadband SLDs, integrating an optical amplifier section has been demonstrated to be a very successful approach (Wang et al, 2011).

\section{Conclusion}

Broadband superluminescent diodes with central wavelengths around 1060nm have received considerable attention during the last few years due to their potential application in ultrahigh resolution OCT imaging systems for microstructural and biological tissues. Different approaches were proposed to engineer the bandwidth of the SLDs, using quantum wells and/or quantum dot structures. Ultrawide bandwidth emission spectra with output power of a few milliwatts were demonstrated. A calculated axial resolution in air of $2.4 \mu \mathrm{m}$ (Haffouz et al, 2012) is expected from the SLDs with widest bandwidth and central wavelength around $1060 \pm 40 \mathrm{~nm}$. This lateral (axial) resolution is approaching that observed when using the state of the art but bulky and expensive femtosecond laser sources (Wang et al, 2003). To achieve finer axial resolution at central wavelength around 1060nm with the use of superluminescent diodes, one needs to further improve the design of the quantum dot and/or quantum well active region of the device, for allowing a wider bandwidth and higher output power, thus opening possibilities for OCT imaging with $1-2 \mu \mathrm{m}$ axial resolution range.

\section{References}

Babinski A., Jasinski J., Bozek R., Szepielow A., \& Baranowski J. M. (2001). Rapid thermal annealing of InAs/GaAs quantum dots under a GaAs proximity cap. Applied Physics Letters, Vol. 79, No. 16 (October 2001), pp. 2576-2578.

Burns W.K., Chen C.L., \& Moeller R.P. (1983). Fiber optic gyroscope with broadband sources. IEEE Journal of Lightwave Technology, Vol. LT-1, No.1 (March 1983), pp.98105.

Friebele E.J., \& Kersey A.D. (1994). Fiberoptic sensors measure up for smart structures. Laser Focus World, Vol.30, No.5 (May 1994), pp.165-169.

Culter C.C., Newton S.A., Show H.J. (1980). Limitation of rotation sensing by scattering. Optics Letters, Vol.5, No.11 (November 1980), pp. 488-490. 
Drexler W., Morgner U., Kartner F. X., Pitris C., Boppart S. A., Li X. D., Ippen E. P., \& Fujimoto J. G. (1999). In vivo ultrahigh-resolution optical coherence tomography. Optics Letters, Vol.24, No.24 (September 1999), pp.1221-1223.

Drexler, W., \& Fujimoto J. G. (2008). Optical coherence tomography: Technology and applications. Springer Berlin Heidelberg New York, 978-3-540-77549-2, Berlin, 2008.

Fafard S., Wasilewski Z. R., Allen C. Ni., Picard D., Spanner M., McCaffrey J. P., \& Piva P. G., (1999). Manipulating the energy levels of semiconductor quantum dots. Physics Review B, Vol.59, No.23 (June 1999), pp. 15368-15373.

Fercher A.F., Hitzenberger C.K., Drexler W., Kamp G., \& Sattmann H. (1993). In vivo optical coherence tomography. American Journal of Ophthalmology. Vol.116, No.1, (1993), pp.113-116.

Garcia J. M., Mankad T., Holtz P. O., Wellman P. J., \& Pettrof P. M. (1997). Electronic states tuning of InAs self-assembled quantum dots. Applied Physics Letters, Vol.72, No.24 (June 1998), p. 3172-3174.

Guol S.-H., Wang Jr-H., Wu Y.-H., Lin W., Y.-J., Sun C.-K., Pan C.-L., \& Shi J.-W. (2009). Bipolar cascade superluminescent diodes at the $1.04 \mu \mathrm{m}$ wavelength regime. IEEE Photonics Technology Letters, Vol.21, No.5 (March 2009), pp. 328-330.

Haffouz S., Raymond S., Lu Z.G., Barrios P.J., Roy-Guay D., Wu X., Liu J. R., \& Poitras D. (2009). Growth and fabrication of quantum dots superluminescent diodes using the indium-flush technique: A new approach in controlling the bandwidth. Journal of Crystal Growth, Vol.311, No.7 (March 2009), pp. 1803-1806.

Haffouz S., Rodermans M., Barrios P.J., Lapointe J., Raymond S., Lu Z.G., \& Poitras D. (2010). Broadband superluminescent diodes with height-engineered InAs-GaAs quantum dots. Electronics Letters, Vol.46, No.16 (August 2010), pp. 1144-1146.

Haffouz S., Barrios P.J., Normandin R., Poitras D., \& Lu Z.G. (2012). Ultrawide bandwidth superluminescent light emitting diodes using InAs quantum dots of tuned height. Optics Letters, Vol. 37, No.6 (March 2012), pp. 1103-1105..

Hartl I., Li X. D., Chudoba C., Ghanta R. K., Ko T. H., Fujimoto J. G., J. K. Ranka and R. S. Windeler (2001). Ultrahigh resolution optical coherence tomography using continuum generation in an air-silica microstructure optical fiber. Optics Letters, Vol.26, N.9 (May 2001), pp.608-610.

Huang D., Swanson E.A., Lin C.P., Schuman J.S., Stinson W.G., Chang W., Hee M.R., Flotte T., Gregory K., Puliafito C.A., Fujimoto J.G. (1991). Optical coherence tomography. Science, Vol.254, (November 1991), pp.1178-1181.

Kosogov A. O., Werner P., Gosele U., Ledentsov N. N., Bimberg D., Ustinov V. M., Egorov A. Y., Zhukov A. E., Kop'ev P. S., Bert N. A., \& Alferov Zh. I. (19996). Structural and optical peoperties of InAs-GaAs quantum dots subjected to high temperature annealing. Applied Physics Letters, Vol. 69, No. 20 (November 1996), pp. 3072-3074.

Koyama F., Liou K. -Y., Dentai A. G., Tanbun-ek T., \& Burrus C. A. (1993). Multiplequantum-well GaInAs/GaInAsP tapered broad-area amplifiers with monolithically integrated waveguide lens for high-power applications. IEEE Photonics Technology Letters, Vol. 5, No. 8 (August 1993), pp. 916-919. 
Leonard D., Krishnamurthy M., Reaves C. M., Denbaars S. P., \& Petroff P. M. (1993). Direct formation of quantum-sized dots from uniform coherent islands of InGaAs on GaAs surfaces. Applied Physics Letters, Vol. 63, No. 23 (December 1993), pp. 32033205,.

Leon R., Kim Y., Yagadish C., Gal M., Zou J., \& Cockayne D. J. H. (1996). Effects of interdiffusion on the luminescence of InGaAs/GaAs quantum dots. Applied Physics Letters, Vol. 69, No. 13 (September 1996), pp. 1888-1890.

Li L. H., Rossetti M., Fiore A., Occhi L., \& Velez C. (2005). Wide emission spectrum from superluminescent diodes with chirped quantum dot multilayers. Electronics Letters, Vol.41, No.1 (January 2005), pp. 41-43.

Liu N., Jin P., \& Wang Z.-G. (2005). InAs/GaAs quantum-dot superluminescent diodes with 110nm bandwidth. Electronics Letters, Vol.41, No.25, (December 2005), pp. 14001402.

Lv X. Q., Liu N., \& Wang Z. G. (2008). Broadband emitting superluminescent diodes with InAs quantum dots in AlGaAs matrix. IEEE Photonics Technology Letters, Vol.20, No.20 (October 2008), pp. 1742-1744.

Malik S., Roberts C., Murray R., \& Pate M. (1997). Tuning self-assembled InAs quantum dots by rapid thermal annealing. Applied Physics Letters, Vol. 71, No. 14 (October 1997), pp. 1987-1989.

Middlemast I., Sarma J., \& Ynus S. (1997). High power tapered superluminescent diodes using novel etched deflectors. Electronics Letters, Vol. 33, No. 10 (May 1997), pp. 903-904.

Pavazay B., Bizheva K., Hermann B., Unterhuber A., Sattmann H., Fercher A.F., Drexler W., Schubert C., Ahnelt P.K., Mei M., Holzwarth R., Wadsworth W. J., Knight J. C., Russel P. St. J. (2003). Enhanced visualization of choroidal vessels using ultrahigh resolution ophthalmic OCT at $1050 \mathrm{~nm}$. Optics Express, Vol.11, No.17 (August 2003), pp.1980-1986.

Povazay B., Hermann B., Unterhuber A., Hofer B., Sattmann H., Zeiler F., Morgan J.E., Falkner-Radler C., Glittenberg C., Blinder S., \& Drexler W. (2007). Threedimensional optical coherence tomography at $1050 \mathrm{~nm}$ versus $800 \mathrm{~nm}$ in retinal pathologies: enhanced performance and choroidal penetration in cataract patients. Journal of Biomedical Optics, Vol.12, No.4 (July/August 2007), pp.04211041211-7.

Ray S.K., Groom K.M., Beattie M.D., Liu H.Y., Hopkinson M., \& Hogg R.A. (2006). Broadband superluminescent light-emitting diodes incorporating quantum dots in compositionally modulated wells. IEEE Photonics Technology Letters, Vol.18, No.1 (January 2006), pp. 58-60.

Ray S.K., Choi T. L., Groom K. M., Stevens B. J., Liu H., Hopkinson M., \& Hogg R. A. (2007). High-power and broadband quantum dot superluminescent diodes centered at $1250 \mathrm{~nm}$ for optical coherence tomography. IEEE Journal of Selected Topics in Quantum Electronics, Vol.13, No.5 (September/October 2007), pp. 12671272. 
Sun Z.-Z., Ding D., Gomg Q., Zhou W., Xu B., \& Wang Z.-G. (1999). Quantum-dot superluminescent diode: A proposal for an ultra-wide output spectrum. Optical and Quantum Electronics, Vol.31, (1999), pp. 1235-1246.

Swanson E. A., Izatt J. A., Hee M. R., Huang D., Lin C. P., Schuman J. S., Puliafito C. A., \& Fujimoto J. G. (1993). In vivo retinal imaging by optical coherence tomography. Optics Letters, Vol.18, No.21 (November 1993), pp.1864-1866.

Takada K., Yokohama I., Chida K., \& Noda J. (1987). New measurement systems for fault location in optical waveguide devices based on an interferometric technique. Applied Optics, Vol.26, No.9 (May 1987) pp. 1603-1606.

Wang Y., Zhao Y., Nelson J. S., \& Chen Z. (2003). Ultrahigh-resolution optical coherence tomography by broadband continuum generation from a photonic crystal fiber. Optics Letters, Vol.11, No.3 (February 2003), pp. 182-184.

Wang L., Rastelli A., \& Schmidt O. G. (2006). Structural and optical properties of In(Ga)As/GaAs quantun dots treated by partial capping and annealing. Journal of Applied Physics, Vol.100, pp.064313_1-064313_4.

Wang Z.C., Jin P., Lv X.Q., Li X.K. \& Wang Z.G. (2011). High-power quantum dot superluminescent diode with integrated optical amplifier section. Electronics Letters, Vol.47, No.21 (October 2011), pp. 1191-1193.

Wasilewski Z. R., Fafard S., \& McCaffrey J. P., (1999). Size and shape engineering of vertically stacked self-assembled quantum dots. Journal of Crystal growth, Vol.201/202, (1999), pp. 1131-1135.

Wasilewski Z. R., Baribeau J.-M., Beaulieu M., Wu X., \& Sproule G. I. (2004). Studies of oxide desorption from $\mathrm{GaAs}$ substrates via $\mathrm{Ga} 2 \mathrm{O} 3$ to $\mathrm{Ga} 2 \mathrm{O}$ conversion by exposure to $\mathrm{Ga}$ flux. Journal of Vacuum Science and technology B, Vol.22, No.3 (May/June 2004), pp. 1534-1538.

Xin Y,-C., Martinez A., Saiz T., Moscho A.J., Li Y., Nilsen T.A., Gray A.L., \& Lester L.F. (2007). $1.3 \mu \mathrm{m}$ quantum-dot multisection superluminescent diodes with extremely broad bandwidth. IEEE Photonics Technology Letters, Vol.19, No.7 (April 2007), pp. 501-503.

Xu S. J., Wang X. C., Chua S. J., Wang C. H., Fan W. J., Jiang J., \& Xie X. G. (1998). Effects of rapid thermal annealing on structure and luminescence of self-assembled InAs/GaAs quantum dots, Applied Physics Letters, Vol. 72, No. 25 (June 1998), pp. 3335-3337.

Yamatoya T., Mori S., Koyama F., \& Iga K. (1999). High power GaInAsP/InP strained quantum well superluminescent diode with tapered active region. Japanese Journal of Applied Physics, Vol. 38, No. 9A (September 1999), pp. 5121-5122.

Yang T., Tatebayashi J., Aoki K., Nishioka M., \& Arakawa Y. (2007). Effects of rapid thermal annealing on the emission properties of highly uniform self-assembled InAs/GaAs quantum dots emitting at $1.3 \mu \mathrm{m}$, Applied Physics Letters, Vol. 90, pp. 111912_1111912_3.

Yoo Y. C., Han I. K., \& Lee J. I. (2007). High power broadband superluminescent diodes with chirped multiple quantum dots. Electronics Letters, Vol. 43, No.19 (September 2007), pp. 1045-1047. 
Zhang Z. Y., Hogg R. A., Xu B., Jin P., \& Wang Z. G. (2008). Realization of extremely broadband quantum-dot superluminescent light-emitting diodes by rapid thermalannealing process. Optics Letters, Vol.33, No.11 (June 2008), pp.1210-1212. 


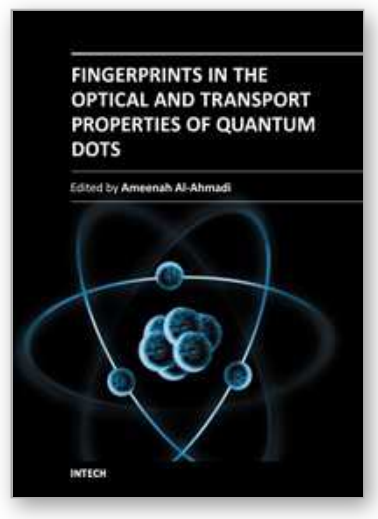

\section{Fingerprints in the Optical and Transport Properties of Quantum Dots}

Edited by Dr. Ameenah Al-Ahmadi

ISBN 978-953-51-0648-7

Hard cover, 468 pages

Publisher InTech

Published online 13, June, 2012

Published in print edition June, 2012

The book "Fingerprints in the optical and transport properties of quantum dots" provides novel and efficient methods for the calculation and investigating of the optical and transport properties of quantum dot systems. This book is divided into two sections. In section 1 includes ten chapters where novel optical properties are discussed. In section 2 involve eight chapters that investigate and model the most important effects of transport and electronics properties of quantum dot systems This is a collaborative book sharing and providing fundamental research such as the one conducted in Physics, Chemistry, Material Science, with a base text that could serve as a reference in research by presenting up-to-date research work on the field of quantum dot systems.

\section{How to reference}

In order to correctly reference this scholarly work, feel free to copy and paste the following:

S. Haffouz and P.J. Barrios (2012). InAs Quantum Dots of Engineered Height for Fabrication of Broadband Superluminescent Diodes, Fingerprints in the Optical and Transport Properties of Quantum Dots, Dr. Ameenah Al-Ahmadi (Ed.), ISBN: 978-953-51-0648-7, InTech, Available from:

http://www.intechopen.com/books/fingerprints-in-the-optical-and-transport-properties-of-quantum-dots/inasquantum-dots-of-engineered-height-for-fabrication-of-broadband-superluminescent-diodes

\section{INTECH}

open science | open minds

\author{
InTech Europe \\ University Campus STeP Ri \\ Slavka Krautzeka 83/A \\ 51000 Rijeka, Croatia \\ Phone: +385 (51) 770447 \\ Fax: +385 (51) 686166 \\ www.intechopen.com
}

\author{
InTech China \\ Unit 405, Office Block, Hotel Equatorial Shanghai \\ No.65, Yan An Road (West), Shanghai, 200040, China \\ 中国上海市延安西路65号上海国际贵都大饭店办公楼 405 单元 \\ Phone: +86-21-62489820 \\ Fax: +86-21-62489821
}


(C) 2012 The Author(s). Licensee IntechOpen. This is an open access article distributed under the terms of the Creative Commons Attribution 3.0 License, which permits unrestricted use, distribution, and reproduction in any medium, provided the original work is properly cited. 